\title{
Relating the structural, air-water interfacial and foaming properties of wheat (Triticum aestivum L.) gliadin and maize (Zea mays L.) zein based nanoparticle suspensions
}

Arno G.B. Wouters ${ }^{a, *}$, Sabine Schaefer ${ }^{a}$, Iris J. Joye ${ }^{a, b}$ and Jan A. Delcour ${ }^{a}$

a Laboratory of Food Chemistry and Biochemistry and Leuven Food Science and Nutrition

Research Center (LFoRCe), KU Leuven, Kasteelpark Arenberg 20, B-3001 Leuven, Belgium.

${ }^{b}$ Food Science Department, University of Guelph, 50 Stone Road East Guelph, Ontario, N1G 2W1, Canada.

*Corresponding author.

Tel.: +32 (0) 16372035

E-mail address: arno.wouters@kuleuven.be

Keywords: Air-water interface, gliadin, zein, nanoparticles, foam, surface hydrophobicity 


\section{INTRODUCTION}

3 Air-in-water or oil-in-water dispersions such as foams and emulsions determine the texture and

4 organoleptic properties of food products such as sauces, margarines, salad dressings, meringues,

5 chocolate mousses, coffee foams and many more. Traditionally, foams and emulsions are

6 stabilized by low molecular mass surfactants [1,2] or proteins $[1,3]$. Their amphiphilicity allows

7 them to adsorb at oil-water or air-water interfaces and to thereby exert stabilizing effects.

8 Alternatively, interfaces may be stabilized by solid particles. Such mechanism has been

9 introduced in the early 1900s [4, 5] and is often referred to as Pickering stabilization. Upon

10 adsorption of particles at an interface, they form a strong mechanical barrier which results in very

11 high resistance against coalescence and disproportionation [6, 7, 8, 9]. However, not all particles

12 adsorb at fluid interfaces equally effectively as they must have some affinity for both phases of

13 the dispersion [10].

14 The affinity of a particle for the phases ( $\alpha$ and $\beta$ ) of a dispersion is characterized by its contact

15 angle $\left(\theta_{\alpha \beta}\right)$ at the interface [7]. When $\theta_{\alpha \beta}=90^{\circ}$, a particle has an equal affinity for both phases.

16 Once adsorbed, the energy needed for a spherical particle to desorb from an interface between

17 two fluids is given by

$$
E=\pi r^{2} \gamma_{\alpha \beta}\left(1-\left|\cos \theta_{\alpha \beta}\right|\right)^{2}
$$

19 in which $r$ is the radius of the particle and $\gamma_{\alpha \beta}$ the surface tension between both immiscible phases

$20[7,9]$. Provided that the contact angle is between $30^{\circ}$ and $150^{\circ}$ and that the particles have

21 dimensions in a $1 \mathrm{~nm}$ to $1 \mu \mathrm{m}$ range, the desorption energy is several orders of magnitude larger 
22 than the thermal energy of Brownian motion. This results in such particles being practically 23 irreversibly adsorbed [7, 8, 10].

24 Thus far, research on particle-stabilized emulsions and foams has mostly focused on particles 25 based on silica [11] or latex [12]. However, such particles can be used neither in pharmaceutical nor in food systems. Over the past few years, the research focus in this field has shifted towards food-grade, biodegradable particles. Examples of such particles include modified fat crystals and polysaccharides [13]. However, proteins (which in many instances are quite surface-active and possess inherent molecular flexibility) are a very promising class of food-grade material for producing nanoparticles (NPs) or microparticles [14].

31 Animal proteins are used in a variety of food systems. While they have excellent functional and 32 nutritional properties, their production is associated with high costs [15] and environmental 33 impacts $[16,17,18]$. As a result, interest in and research on plant proteins and their functional 34 properties have risen substantially over the past decade [19, 20]. As part of this general trend, 35 the possibility to use them to produce particles has been investigated. The focus thus far has often been on encapsulating active compounds for controlled release or improved stability throughout

37 the digestion tract [21]. However, as described above, such particles can also stabilize foams and 38 emulsions.

39 A very promising approach for producing protein particle dispersions is liquid anti-solvent 40 precipitation [21]. In such procedure, the quality of the solvent in which a protein is dissolved, is 41 decreased by adding a second liquid. This leads to controlled protein aggregation and under 42 appropriate conditions to homogeneously dispersed NP suspensions [21]. Other advantages of 43 such approach include its high reproducibility and tunability in terms of particle size. Furthermore, 
44 no specialized equipment is required and the technique is up-scalable and industrially feasible

45 [21]. Protein NPs produced this way include, amongst others, those from wheat gliadins [22, 23,

$4624,25]$, maize zeins [26, 27, 28, 29], sorghum kafirins [30] and whey proteins [22].

47 Several studies have dealt with the use of such particles for stabilizing interfaces in a food context.

48 de Folter et al. [27] were amongst the first to report on zein NP stabilized oil-in-water emulsions.

49 However, their stability was not as high as brought about by other stabilizing agents. It has been

50 suggested that zein NPs are too hydrophobic too efficiently stabilize oil-water interfaces. Several

51 modification strategies to alter both particle hydrophobicity and colloidal stability in food system

52 relevant conditions have been described. These include addition of surfactants [31], tannic acid

53 [29, 32], gum arabic [33], chitosan [34] or sodium caseinate [35]. Similarly, NPs based on wheat

54 gliadins have been used to stabilize emulsions [23] and foams [25, 36]. Such gliadin NP stabilized

55 dispersions are relatively stable, although the colloidal stability of the particles themselves under

56 food system relevant conditions is still quite low [37].

57 In this area, there are still several knowledge gaps. First, most studies using plant protein based

58 NPs for interfacial stabilization were on emulsions rather than on foams. Second, the structure-

59 function relation of these particles should be further explored. Third, much is still to be learned

60 about the behavior of such particles at interfaces. As described above, rigid solid particles can

61 exert 'Pickering' type stabilization, while dissolved proteins adsorb and form viscoelastic films at

62 the interface. It largely remains to be investigated how protein based NPs behave at such

63 interfaces.

64 In the present paper we investigate the air-water interface stabilization by NPs based on the plant

65 prolamins gliadin and zein and focus on the differences between wheat gliadin and zein based 
NPs (WGNPs and MZNPs respectively) both in terms of structural features [size, surface charge,

67 surface hydrophobicity $(\mathrm{SH})$ ] and their ability to stabilize air-water interfaces. As endogenously

68 present lipids may impact particle formation and/or NP functionality, a defatting procedure was

69 employed to study the impact of these lipids. Finally, mixed gliadin-zein NPs were studied to

70 better understand the relationship between structure and function of protein based NPs. A

71 thorough and comprehensive approach such as the one used here is imperative for a better

72 understanding of the structure-function relationship of protein based NP suspensions and their

73 behavior in food systems.

\section{MATERIALS AND METHODS}

76

\subsection{Materials}

Wheat gluten powder was kindly provided by Tereos Syral (Aalst, Belgium) and maize zein powder was from Sigma-Aldrich (Bornem, Belgium). They respectively contained $79.7 \%(\mathrm{~N} \times 5.7)$ and 94.5\% ( $\mathrm{N} \times 6.25)$ protein on dry matter $(\mathrm{dm})$ basis as determined using an adaptation of AOAC Official Method 990.03 [38] to an EA1108 Elemental Analyzer (Carlo Erba/Thermo Scientific, Waltham, MA, USA). Their respective moisture contents [determined with AACCI International Method 44-19.01 [39]] were 5.3\% and 5.0\% on dm basis. Gliadin was extracted from wheat gluten using $70.0 \% \mathrm{v} / \mathrm{v}$ aqueous ethanol. Extracts were obtained in a gluten to solvent ratio of 1:10 (w:v) by shaking at room temperature for $60 \mathrm{~min}$ followed by centrifugation ( $12,000 \mathrm{~g}$ for $10 \mathrm{~min}$ ) and filtration of the supernatant. Ethanol was removed by rotary evaporation under partial vacuum 
at $40{ }^{\circ} \mathrm{C}$ and the resultant suspension was frozen with liquid nitrogen and freeze dried. The resulting gliadin powder had a protein content of $86.5 \%$ (determined as above, $\mathrm{N} \times 5.7$ ) on dry matter basis. All chemicals, solvents and reagents were from Sigma-Aldrich unless specified otherwise. All filtrations were with Whatman (Maidstone, UK) paper filters (pore size 4-7 $\mu \mathrm{m}$ ).

\subsection{Defatting of gliadin and zein powders}

Gliadin and zein powders (see section 2.1) were defatted based on a protocol described by Bligh

\& Dyer [40]. Samples (300 mg) were accurately weighed in a test tube, after which $2.0 \mathrm{~mL}$ chloroform, $2.0 \mathrm{~mL}$ methanol and $1.8 \mathrm{~mL}$ deionized water were sequentially added. After addition of each individual solvent, the test tubes were vigorously shaken. After centrifugation [20 min, $500 \mathrm{~g}$, room temperature $\left(23^{\circ} \mathrm{C}\right)$ ], a lower lipid containing chloroform phase and an upper nonlipid material containing methanol-water phase separated by a residue could be distinguished. The upper and lower phases were isolated separately in tared test tubes and the extraction was repeated on the residue, after which the chloroform and methanol-water phases from both extractions were each pooled. The chloroform was evaporated with a rotary vacuum concentrator (Martin Christ, Osterode am Harz, Germany) and the resultant lipid extract accurately weighed. The methanol-water phases were added back to the pooled residues. The methanol was removed through rotary evaporation under partial vacuum at $40^{\circ} \mathrm{C}$. The defatted gliadin and zein were then obtained by subsequent freeze-drying as outlined above. 
110 investigate the impact of the solvent treatment associated with the defatting procedure on the

111 non-lipid gliadin and zein powder constituents. Such samples are further referred to as 'treated'

112 samples. Both defatted and treated samples were prepared in six-fold and pooled prior to use for

113 NP production.

\subsection{Production of nanoparticles}

WGNPs and MZNPs were obtained by liquid anti-solvent precipitation. Stock solutions containing

$2.50 \%$ gliadin or zein protein (prepared from their powders as well as from their defatted or

119 treated powders, see section 2.2) were prepared in $70.0 \% \mathrm{v} / \mathrm{v}$ aqueous ethanol. Also prepared

120 were stock solutions containing $1.88 \%$ gliadin protein and $0.063 \%$ zein protein or $1.25 \%$ gliadin

121 and $1.25 \%$ zein protein in $70.0 \% \mathrm{v} / \mathrm{v}$ aqueous ethanol. To produce particles, an aliquot $(2.0 \mathrm{~mL})$ of

122 the respective stock solutions was added dropwise over a 10 s period above the center of a beaker

123 (internal diameter $6.5 \mathrm{~cm}$ ) containing $28.0 \mathrm{~mL}$ deionized water while continuously stirring at 440

$124 \mathrm{rpm}$. The particle suspension was then stirred for an additional $30 \mathrm{~s}$. The resulting suspensions

125 were diluted with $4.67 \% \mathrm{v} / \mathrm{v}$ aqueous ethanol to obtain a protein concentration of $0.10 \%$ for

126 further analyses. All further mentions of NPs based on gliadin (WGNPs) and zein (MZNPs) stock

127 solutions, defatted or treated gliadin (D-WGNPs and T-WGNPs) or zein (D-MZNPs and T-MZNPs)

128 stock solutions or mixed gliadin-zein (e.g. WGNP ${ }_{75} \mathrm{MZNP}_{25}$ refers to a sample based on a stock

129 solution of $1.88 \%$ gliadin and $0.063 \%$ zein protein) stock solutions refer to such diluted

130 suspensions. WGNP and MZNP suspensions had $\mathrm{pH}$ values of 6.0 and 4.5 , respectively. WGNP 
131 suspensions at $\mathrm{pH} 4.5$ and MZNP suspensions at $\mathrm{pH} 5.5$ were also prepared by adding $0.1 \mathrm{M} \mathrm{HCL}$

132 or $0.1 \mathrm{M} \mathrm{NaOH}$ to freshly prepared particle suspensions.

\subsection{Measurement of particle size, polydispersity and zeta potential}

136 Particle size distribution and polydispersity-index (PDI) measurements were based on dynamic 137 light scattering and zeta potential (ZP) measurements on laser Doppler electrophoresis. All above 138 described NP suspensions (see section 2.3) were transferred to a disposable capillary zeta cell

139 (Malvern Instruments, Malvern, United Kingdom) to then determine the particle size distribution 140 and ZP in a Malvern Zetasizer Nano ZS. Particle size measurements yielded scattering patterns 141 which were converted into a correlation function which provides information on the diffusion 142 coefficients of the dispersions. The latter then allowed calculating particle size distributions with 143 the Stokes-Einstein relationship using the Malvern Zetasizer software. For ZP measurements an 144 electrical field was applied which caused particles to move at a rate which depends on their 145 charge. The resulting scattering pattern allowed determining the electrophoretic mobility and the 146 ZP value, the latter with the above mentioned software. Measurements were at room 147 temperature $\left(23 \pm 2{ }^{\circ} \mathrm{C}\right)$. The viscosity of $4.67 \% \mathrm{v} / \mathrm{v}$ ethanol was $1.0038 \mathrm{mPa} . \mathrm{s}$ [calculated based 148 on Khattab, Bandarkar, Fakhree \& Jouyban [41]], its refractive index was 1.335 [extrapolated 149 from experimental values obtained by Belda, Herraez \& Diaz [42]], and its dielectric constant 76.2 150 [calculated as in Akerlof [43]]. 
154 NP surface characteristics were assessed using intrinsic and extrinsic fluorescence measurements.

155 Intrinsic fluorescence was based on the emission of fluorescent light by tryptophan and tyrosine

156 residues in the proteins. All above described NP suspensions (see section 2.3) at a concentration

157 of $0.01 \%$ protein were transferred to a quartz cuvette and introduced in a Fluoromax 4

158 fluorospectrophotometer (Horiba Jobin Yvon, Edison, NJ, USA). The excitation wavelength was

$159280 \mathrm{~nm}$ with a $2 \mathrm{~nm}$ slit width and the emission spectrum was recorded from 290 to $410 \mathrm{~nm}$ with

160 the same slit width. The spectrum of $4.67 \% \mathrm{v} / \mathrm{v}$ ethanol was subtracted from spectra obtained for

161 samples. Extrinsic fluorescent measurements were performed by using the uncharged

162 hydrophobic fluorescent probe 6-propionyl-2-dimethylaminonaphthalene (PRODAN) and the

163 recorded maximum emission intensities were indicative for the SH of the NPs. A $2.0 \mathrm{~mL}$ aliquot of

164 each of the above described NP suspensions (see section 2.3) at a concentration of $0.03 \%$ protein

165 were incubated for 5 min in the dark with $10 \mu \mathrm{L} 0.1025 \mathrm{mM}$ PRODAN in methanol. These samples

166 were transferred to a quartz cuvette and analyzed by fluorospectrophotometry as above. The

167 excitation wavelength was $365 \mathrm{~nm}$ with a $4 \mathrm{~nm}$ slit width and the emission spectrum recorded

168 from 390 to $590 \mathrm{~nm}$ with the same slit width. The spectrum of $4.67 \% \mathrm{v} / \mathrm{v}$ ethanol incubated with

169 PRODAN in the same way was subtracted from all sample spectra. All measurements were

170 conducted at a protein concentration which rendered a fluorescent signal in the linear range.

171 Measurements were conducted at room temperature $\left(23 \pm 2{ }^{\circ} \mathrm{C}\right)$.

172

\subsection{Foaming characteristics}

174

175 Foaming properties were determined with the stirring test used earlier by Wouters et al. [44]. An

176 aliquot $(50.0 \mathrm{~mL})$ of the above described (section 2.3$)$ NP suspensions $(0.10 \%$ protein in $4.67 \% \mathrm{v} / \mathrm{v}$ 
177 ethanol) was placed in a graduated glass cylinder (internal diameter $60.0 \mathrm{~mm}$ ) in a water bath at

$17825^{\circ} \mathrm{C}$. After equilibration for $15 \mathrm{~min}$, the NP suspension was stirred for $70 \mathrm{~s}$ at $2,000 \mathrm{rpm}$ using an

179 in-house made propeller (outer diameter $45.0 \mathrm{~mm}$, thickness $0.4 \mathrm{~mm}$ ). After stirring, the 180 propeller was immediately removed and the glass cylinder sealed with Parafilm M (Bemis, 181 Neenah, WI, USA) to avoid foam disruption by air circulation. Foam heights of WGNP and MZNP 182 suspensions were measured after $2,4,10,15,30,45,60,120,240,480$ and 1,440 min after the 183 start of stirring. Foam heights of all other samples were measured up to 60 min after the start of 184 stirring. This was sufficient to distinguish between samples. Foam volumes (in $\mathrm{mL}$ ) were calculated 185 from foam heights and the cylinder internal diameter. The foaming capacity was assessed as the 186 foam volume 2 min after the start of whipping, while foam stability was assessed as the evolution 187 of the foam volume over time.

\section{7 (Oscillating) pendant drop measurements}

191 (Oscillating) pendant drop measurements were performed in a procedure similar to that of 192 Wouters et al. [45]. All above described (section 2.3) NP suspensions (0.10\% protein in $4.67 \% \mathrm{v} / \mathrm{v}$ 193 ethanol) were introduced in a Theta optical tensiometer (Biolin Scientific Attension, Stockholm, 194 Sweden) to create a pendant drop with a fixed volume of $8 \mu \mathrm{L}$. In a first type of measurement, 195 surface tension $\gamma$ of the pendant drop was recorded over the course of 10 min based on drop 196 shape analysis and a Young-Laplace fit. During the measurements, images were recorded at one 197 frame per $7 \mathrm{~s}$. In a second type of measurement a sinusoidal oscillation of the drop (5 cycles) at $1980.5 \mathrm{~Hz}$ with an amplitude set at 1.00 in the OneAttension software (Biolin Scientific Attension) was performed at several time points after drop creation. The set amplitude corresponded to a 
200 volume change of $\pm 1 \mu \mathrm{L}$ and was within the linear regime. During such oscillations, images were 201 recorded at 7 frames per s. The first oscillatory measurement took place $15 \mathrm{~s}$ after drop formation 202 with subsequent measurements every $15 \mathrm{~s}$ thereafter until $5 \mathrm{~min}$ after drop formation. From that 203 moment on, a measurement was performed every min until 10 min after drop formation, at which 204 point the measurements were concluded. Based on drop shape analysis during oscillation, the 205 surface dilatational modulus $E$ could be determined. $E$ is the variation in surface tension $\gamma$ per unit 206 relative change in surface area $(\mathrm{A})[46,47]$. The following relation holds

$$
E=\frac{d \gamma}{d \ln A}
$$

$208 E$ is a viscoelastic complex quantity. It consists of a real surface dilatational elastic ( $\left.E^{\prime}\right)$ and an 209 imaginary dilatational viscous $\left(E^{\prime \prime}\right)$ contribution, of which the latter is given by the product of a 210 surface dilatational viscosity $\left(\eta_{d}\right)$ and the frequency $(\omega)$ of the variation in $A[46,47]$.

$$
E=E^{\prime}+i E^{\prime \prime}=E^{\prime}+i \omega \eta_{d}
$$

212 Both surface dilatational elastic and viscous moduli E' and E" are reported here. After each 213 measurement, the device was thoroughly cleaned and the surface tension of pure water was 214 checked to be $72.0 \pm 0.5 \mathrm{mN} / \mathrm{m}$ before initiating the next measurement.

\subsection{Statistical analyses}

218 All determinations of particle size, ZP, fluorescent measurements, foaming properties and 219 oscillating pendant drop measurements were at least in four-fold. Error bars and values represent 220 standard deviations from the mean. All data was analyzed using statistical software JMP Pro 12 221 (SAS Institute, Cary, NC, USA). One way analysis of variance (ANOVA) was performed followed by 

$\mathrm{pH} 5.5$ had a more homogeneous size distribution than at $\mathrm{pH}$ 4.5. Similar observations were made

a Tukey multiple comparison test as post-hoc analysis to detect significant differences (both at a significance level $\mathrm{P}=0.05)$.

\section{RESULTS AND DISCUSSION}

\subsection{Structural and functional characteristics of gliadin and zein based nanoparticles}

Table 1 shows average values for the size (Z-average), PDI and ZP of WGNP and MZNP suspensions, immediately after production. WGNP and MZNP suspensions had pH 6.0 and pH 4.5 respectively and are further referred to as $\mathrm{pH}$ unadjusted samples. All particles were stable (no changes in size, PDI or ZP; data not shown) for at least 24 hours after production. Nonetheless, all analyses were carried out on freshly produced NP suspensions. pH unadjusted WGNPs were larger $(\mathrm{P}<0.05)$ than $\mathrm{pH}$ unadjusted MZNPs while the latter had a higher $(\mathrm{P}<0.05)$ PDI value and thus a less homogeneous particle size distribution than the former. Furthermore, $\mathrm{pH}$ unadjusted MZNPs had much higher $(\mathrm{P}<0.05)$ ZP than $\mathrm{pH}$ unadjusted WGNPs. As mentioned, $\mathrm{pH}$ unadjusted WGNP and MZNP suspensions had pH values of 6.0 and 4.5, respectively, which likely explains the higher ZP of the latter. For the sake of rational comparison between samples, Table 1 also shows size, PDI and ZP of WGNPs at $\mathrm{pH} 4.5$ and MZNPs at $\mathrm{pH}$ 5.5. The latter $\mathrm{pH}$ rather than $\mathrm{pH} 6.0$ was chosen and deemed a valid basis for comparison because MZNP precipitate at a $\mathrm{pH}$ of about 5.7. Indeed, MZNPs at $\mathrm{pH} 5.5$ were larger and had much lower $\mathrm{ZP}(\mathrm{P}<0.05)$ than at $\mathrm{pH}$ 4.5. This of course is related to the proximity to the point-of-zero-charge at $\mathrm{pH} 5.5$. Interestingly, MZNPs at for WGNPs. They had higher PDI and higher ZP $(\mathrm{P}<0.05)$ at $\mathrm{pH} 4.5$ than at $\mathrm{pH}$ 6.0. Nevertheless, 
245 there was no significant $(P>0.05)$ difference in size between WGNPs at pH 4.5 or pH 6.0. Also, 246 the ZP of WGNPs at $\mathrm{pH} 4.5$ was still substantially lower $(\mathrm{P}<0.05)$ than that of MZNPs at the same $247 \mathrm{pH}$.

249 Figure 1 shows intrinsic and extrinsic fluorescence spectra of WGNP [pH 4.5 and $\mathrm{pH} 6.0(\mathrm{pH}$ 250 unadjusted)] and MZNP [pH 4.5 ( $\mathrm{pH}$ unadjusted) and $\mathrm{pH}$ 5.5]. Excitation of intrinsically present 251 fluorophores in the protein (such as tryptophan and tyrosine) results in fluorescence of which 252 both the intensity and the wavelength of maximal intensity provide information on the local 253 environment of these fluorophores and thus on the conformational or aggregation state of the 254 protein NPs [48]. Typically, exposure of proteins to $280 \mathrm{~nm}$ light results in excitation of both 255 tyrosine and tryptophan residues.

256 In the present case, $\mathrm{pH}$ unadjusted WGNPs showed a maximal fluorescence intensity at about 352 $257 \mathrm{~nm}$, which is typical for the emission by tryptophan [49]. At about $310 \mathrm{~nm}$, which is close to the 258 wavelength at which tyrosine typically emits light after excitation at $280 \mathrm{~nm}$ [49], only a slight 259 inflection in the fluorescence spectrum was observed. Thus, the fluorescent signal of WGNPs is 260 dominated by tryptophan residues even though tryptophan and tyrosine respectively make up 261 about $0.4 \%$ and $2.0 \%$ (on a molar basis) of the amino acids in the wheat prolamin fraction [50]. 262 This can be explained by the lower molar absorptivity of tyrosine compared to that of tryptophan. 263 Furthermore, tyrosine is sensitive to quenching in the presence of tryptophan [49]. For these 264 reasons, the fluorescence by tyrosine is usually much lower than that of tryptophan when both 265 are present. 
266 In contrast, the fluorescence spectrum of $\mathrm{pH}$ unadjusted MZNP showed maximum emission 267 intensity at $305 \mathrm{~nm}$, which, as mentioned earlier, is consistent with light emission by tyrosine after 268 excitation at $280 \mathrm{~nm}$ [49]. This of course is due to the absence of tryptophan residues in the 269 primary structure of zein proteins [51], while tyrosine residues comprise about 3.6\% (on a molar 270 basis) of the amino acids in zein prolamins [50].

271 Interestingly, there were no differences in maximum fluorescence intensity or maximum intensity 272 wavelength for WGNPs at $\mathrm{pH} 4.5$ and $\mathrm{pH}$ 6.0. However, MZNPs at $\mathrm{pH} 5.5$ had a higher $(\mathrm{P}<0.05)$ 273 fluorescence intensity than at $\mathrm{pH}$ 4.5. MZNPs were larger at $\mathrm{pH} 5.5$ than at $\mathrm{pH} 4.5$ (Table 1). 274 Possibly, swelling of MZNPs in proximity of the point-of-zero-charge altered their tyrosine 275 fluorescent signal. Indeed, Förster distances for resonance energy transfer between tyrosine 276 residues of 0.9-1.6 $\mathrm{nm}$ have been reported [49]. Considering that the average size of MZNPs was 277 approximately $97 \mathrm{~nm}$ at $\mathrm{pH} 4.5$ and approximately $155 \mathrm{~nm}$ at $\mathrm{pH} 5.5$ (Table 1), it is reasonable to 278 assume that energy transfer between tyrosine residues occurred to a lesser extent at $\mathrm{pH} 5.5$, 279 resulting in lower $(\mathrm{P}<0.05)$ fluorescence at $\mathrm{pH} 4.5$ than at $\mathrm{pH}$ 5.5. That WGNPs at $\mathrm{pH} 4.5$ and 6.0 280 had rather similar sizes (Table 1) and fluorescent emission spectra (Figure 1a) to some extent 281 supports this hypothesis.

282 Extrinsic fluorescent signals were obtained by PRODAN binding to hydrophobic patches at the 283 surface of the NPs [52, 53]. Doing so shifted the maximum emission intensity wavelength of 284 unbound PRODAN (at about $520 \mathrm{~nm}$ ) to about $450 \mathrm{~nm}$ [53]. $\mathrm{pH}$ unadjusted MZNPs had much 285 higher $(\mathrm{P}<0.05)$ PRODAN-induced fluorescence intensity and thus $\mathrm{SH}$ than pH unadjusted WGNPS 286 (Figure 1b). Furthermore, differences in $\mathrm{pH}$ did not cause significant differences $(P>0.05)$ in 
fluorescence intensity or in the wavelengths of maximum intensity both for WGNPs and MZNPs. MZNPs thus had higher SH than WGNPs at both pHs.

Figure $2 \mathrm{a}$ shows the foaming properties of suspensions of WGNPs at $\mathrm{pH} 4.5$ and $\mathrm{pH} 6.0(\mathrm{pH}$ unadjusted) and of MZNPs at $\mathrm{pH} 4.5$ ( $\mathrm{pH}$ unadjusted) and $\mathrm{pH}$ 5.5. WGNPs at $\mathrm{pH} 6.0$ had both high foaming capacity as well as extremely high foam stability (section 2.6). Indeed, even after 24 hours almost $60 \%$ of the foam initially formed during stirring remained. In contrast, no foam could be formed with the $\mathrm{pH}$ unadjusted MZNP suspension at $\mathrm{pH}$ 4.5. At $\mathrm{pH}$ 5.5, stirring a MZNP suspension resulted in a limited amount of foam. This foam was very unstable and had already disappeared after 10 min. Stirring of a WGNP suspension at $\mathrm{pH} 4.5$ or $\mathrm{pH} 6.0$ resulted in similar foaming capacities, but the stability of the former foam was somewhat lower than that of the latter. Thus, overall, both for WGNPs and MZNPs foaming capacity and foam stability seemed to be higher at the higher $\mathrm{pH}$. Nonetheless, the difference in foaming properties between WGNPs, which resulted in stable foams, and MZNPs, which had very poor foaming properties, was substantial. Figure 2 also shows surface tension (b), $E^{\prime}$ (c) and $E^{\prime \prime}(d)$ values over the course of 10 min for 302 WGNP (at pH 4.5 and 6.0) and MZNP (at pH 4.5 and 5.5) suspensions. In general, equilibrium 303 surface tension had not yet been reached after $10 \mathrm{~min}$, although the various curves approached 304 a plateau value (Figure 2b). Nevertheless, there were no major differences in surface tension of 305 the differences samples. Only the surface tension curve of WGNP at pH 4.5 was slightly higher 306 than that of the other samples, but the difference was minor. Thus, possible differences in $E^{\prime}$ and $E^{\prime \prime}$ of the different samples cannot be attributed to differences in surface pressure but are solely 
$E^{\prime}$ and $E^{\prime \prime}$ provide information on the dilatational rheology of the air-water interface and thus on

310 the viscoelasticity of the adsorbed layer thereat. E' values were higher than E' values for all

311 samples (Figure 2c-d) implying that the adsorbed layer's interfacial behavior was elastic rather

312 than viscous. Figure $2 c-d$ further shows that, most notably for WGNP, E' and E" increased over

313 time, suggesting the formation of a viscoelastic protein film at the interface. A similar observation

314 was made in a very recent study. Our findings are indeed in line with those of Peng et al. [25] who

315 reported that adsorption of gliadin based NPs at the air-water interface is accompanied by

316 formation of an adsorbed layer with high E values. Interestingly, all this could be related to the

317 foaming characteristics of WGNP and MZNP suspensions. Indeed, samples with high E' values

318 (WGNP suspensions) also had high foaming capacity and foam stability. In general, increases of E'

319 and $E^{\prime \prime}$ for protein solutions is typically associated with continuous adsorption and mutual

320 interaction of protein molecules at the interface which results in a viscoelastic protein film.

321 Additionally, high E values of such adsorbed protein films are often related to the protein's ability

322 to form stable foams [3]. Here, similar observations were made for proteins occurring as a

323 suspension of NPs of which the interfacial behavior has not been thoroughly described earlier.

324 Indeed, very few studies in literature deal with the topic. When solid inert particles adsorb at the

325 interface, generally no coherent elastic layer is formed at the interface. However, for NPs based

326 on the proteins used here, this apparently is the case.

328 In summary, when adsorption of NPs at the interface results in high foaming capacity and foam

329 stability, this is accompanied by the build-up of an adsorbed protein film characterized by high E

330 values in dilatational rheological measurements. Indeed, WGNP suspensions had excellent 
331 foaming properties and high interfacial E values, while MZNP suspensions resulted in very poor

332 foaming and low E values. However, the underlying cause for these observations remains unclear.

333 A likely explanation is that this difference arises from the much higher SH of MZNPs than of

334 WGNPs, as shown by fluorescence spectroscopy, especially since differences in $\mathrm{pH}$ and thus

335 surface charge were not be the determining factor.

336 In what follows, we explore whether the endogenous lipids in wheat gliadin and maize zein

337 powders might be at the basis for the difference in their SH but, more importantly, also of their

338 ability to stabilize air-water interfaces.

\subsection{Role of endogenous wheat and maize lipids}

342 Gliadin and zein powders contained $4.65 \%$ and $6.79 \%$ lipids on dry matter basis, respectively. The

343 impact of these endogenous lipids on particle formation was investigated by defatting the 344 powders prior to particle production. To assess the impact of the solvent treatment associated 345 with the defatting procedure on the other, non-lipid, constituents present in these powders, 346 'treated' samples were also investigated (see section 2.2).

347 Table 2 shows that there were no significant differences in average size between the regular, 348 defatted and treated WGNPs. The same held true for MZNPs. Indeed, PDI values of WGNPs and 349 MZNPs were also not significantly $(P>0.05)$ affected by defatting or 'treatment' of the samples. 350 ZP values of WGNPs, D-WGNPs and T-WGNPs were also not significantly different $(P>0.05)$.

351 The only notable difference here was observed for D-MZNPs, which had significantly lower $(P<$ $3520.05)$ ZP than MZNPs and T-MZNPs. Figure 3a-b shows intrinsic and extrinsic fluorescence spectra 353 of regular, defatted and treated WGNP and MZNP suspensions. There was impact neither on 
354 maximum fluorescence intensity nor on maximum intensity wavelength of the defatting or 355 treatment procedure on WGNP or MZNP suspensions $(P>0.05)$. This was the case both for 356 intrinsic and PRODAN-induced fluorescence.

357 Overall, neither defatting nor the solvent treatment associated therewith seemed to have a 358 notable impact on particle properties (size, PDI, ZP and SH). It thus seems that endogenous lipids 359 do not play a crucial role in particle formation, as has been suggested [24]. Furthermore, 360 treatment with chloroform or methanol had no impact on the proteins in the gliadin and zein 361 powders in terms of their ability to aggregate into NPs when subjected to an anti-solvent 362 precipitation procedure.

364 Figure 4a clearly illustrates that WGNP samples consistently had better foaming properties than 365 MZNP samples. Some foam could be formed by stirring a D-MZNP suspension but after 10 min no 366 foam remained. Stirring of MZNPs and T-MZNPs did not result in any foam. In contrast, WGNPs, 367 D-WGNPs and T-WGNPs all led to similarly high initial foam volumes as well as high foam 368 stabilities. In an attempt to differentiate between the different WGNP samples, an additional 369 foaming test was performed at lower protein concentration (0.030\%, Figure 5a). Here, it seemed 370 that D-WGNP foams possibly had slightly higher stability than those of WGNPs and T-WGNPs, 371 although differences were limited at best. Moreover, the foaming characteristics of MZNPs at pH 3725.5 were slightly better than at $\mathrm{pH}$ 4.5. To further assess the possible impact of $\mathrm{pH}$, Figure $5 \mathrm{~b}$ also 373 shows an additional foam test in which defatted and treated MZNP were tested at pH 5.5. 374 However, this also did not result in improved foaming characteristics. 
375 Figure $4 \mathrm{~b}$ also shows the evolution of surface tension over time for the different regular, treated 376 and defatted samples. In line with what was observed in Figure 2b, surface tension curves of 377 regular and treated WGNPs and MZNPs were very similar. The curves of D-WHNPs and D-MZNPs 378 were characterized by slightly higher surface tensions, which indicates that lipids at least to some 379 extent were present at the air-water interface. More interestingly, foaming properties of the 380 different defatted, treated and regular WGNPs and MZNPs seemed in line with their behavior in 381 interfacial dilatational experiments (Figure 4c-d). Indeed, both E' and E'" values over a 10 min time 382 span of all MZNP samples were substantially lower than E values of the different WGNP samples. 383 While there seemed to be no notable differences between the respective $E^{\prime}$ and $E^{\prime \prime}$ values of 384 WGNPs and T-WGNPS, E' and E" of D-WGNPs increased more pronouncedly over time than did those of WGNPs and T-WGNPs. That D-WGNPs had higher E' and E" values than WGNPs is in line with what is known about the co-occurrence of proteins and lipids at air-water interfaces. Indeed, 387 while proteins adsorb, mutually interact and thereby form a viscoelastic protein film, lipids form 388 a highly mobile fluid monolayer [2]. These two different interfacial phenomena counteract each 389 other when both proteins and lipids co-occur at an interface. This usually results in low interfacial 390 stability [54]. Here, an increase in $E^{\prime}$ and $E^{\prime \prime}$ as a result of removing the lipids from the samples was noted. This suggests that even though lipids do not directly affect particle formation (see 392 above) they do to some extent weaken the adsorbed protein film at the air-water interface. That 393 only slight differences in foam stability between D-WGNPs and WGNPs were observed suggests 394 that this effect is rather small in the present system. Nonetheless, that a similar phenomenon as 395 that described for proteins and lipids in solution seems to occur here may imply that the protein 396 particles upon adsorption at least to some extent disintegrate and 'unfold' at the interface and 
mutually interact to form a viscoelastic protein film. For the different MZNP samples this was not

398 observed probably because $E^{\prime}$ and $E^{\prime \prime}$ of MZNPs were too low to start off with.

399 Thus, the presence of endogenous lipids could not explain the differences in the ability of WGNPs 400 and MZNPs to stabilize air-water interface. Considering that particle size and surface charge (see

401 section 3.1) could not explain these differences, they must arise from differences in the inherent

402 hydrophobicity of the proteins (see Figure 3a-b). Indeed, it has been proposed that zein protein 403 based NPs rapidly aggregate at interfaces, thereby leading to low surface coverage [55]. Similarly, $404 \mathrm{pH}$ unadjusted zein based NPs are poor emulsion stabilizers presumably because of their high 405 hydrophobicity [32]. Nonetheless, removing the lipids from gliadin powder supported the 406 observation that for these protein based NPs to efficiently stabilize interfaces, they need to be 407 able to adsorb, unfold and mutually interact at the interface, which is the case for WGNPs but not 408 for MZNPs.

409 In a final part, mixed gliadin and zein based NPs were produced to assess whether such hybrid 410 particles have improved functionality at the air-water interface. Doing so also allowed further 411 testing our hypothesis regarding the formation of a viscoelastic protein film at the air-water 412 interface and its relation to foam stability.

\subsection{Mixed gliadin-zein nanoparticles}

416 Hybrid gliadin-zein particles were produced by replacing $25 \%$ or $50 \%$ of the gliadin protein in the 417 stock solution by zein protein (see section 2.3). Regular WGNP and MZNP in this section are 418 referred to as $W_{G N P_{100}}$ and $M Z N P_{100}$, respectively. As already mentioned, $W_{G N P_{100}}$ had higher 419 average size than $\mathrm{MZNP}_{100}$. Upon replacement of $25 \%$ of gliadin by zein protein material (resulting 


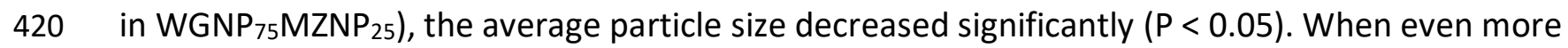

421 zein was present in the stock solution used to produce $W_{G N P_{50}} M_{2 N P_{50}}$ and $M Z N P_{100}$, the particle

422 size seemed to decrease even further, although it was not significantly $(P>0.05)$ different from

423 that of $W_{G N P}{ }_{75} M_{2 N P}$. As could be expected, an opposite trend was observed for the PDI values

424 of the different mixed particles. Indeed, MZNP $_{100}$ had higher PDI than WGNP100, while

425 WGNP $_{75} M_{2 N P_{25}}$ had a PDI similar to that of WGNP 100 and that of WGNP W0MZNP $_{50}$ did not differ

426 significantly $(P>0.05)$ from those of any of the other samples. Finally, ZP of MZNP 100 was much

427 higher $(P<0.05)$ than those of the other samples, which had similar ZP values.

428 Figure 6a-b shows that also in terms of intrinsic and extrinsic (PRODAN induced) fluorescence, a

429 gradual transition from $\mathrm{WGNP}_{100}$ towards $\mathrm{MZNP}_{100}$ was observed. Indeed, while $\mathrm{MZNP}_{100}$ and

430 WGNP $_{100}$ had maximum emission intensities at wavelengths of about $305 \mathrm{~nm}$ and $350 \mathrm{~nm}$,

431 respectively, the mixed gliadin-zein NPs resulted in a fluorescent signal at both wavelengths with

432 intensities intermediate to those of the WGNP $_{100}$ and MZNP $_{100}$ suspensions. Similarly, while

$433 \mathrm{MZNP}_{100}$ had much higher $\mathrm{SH}$ as assessed by PRODAN-induced fluorescence than WGNP 100 , the

434 hydrophobicity of WGNP ${ }_{75} \mathrm{MZNP}_{25}$ and $\mathrm{WGNP}_{50} \mathrm{MZNP}_{50}$ was intermediate between those of these

435 two. Thus, it seemed that by using a stock solution containing both gliadin and zein proteins

436 particles could be produced with surface characteristics intermediate to those of the gliadin and

437 zein only based NPs. Nevertheless, a similar trend was not fully observed in terms of the foaming

438 characteristics of the mixed gliadin-zein NPs (Figure 7a). While at first glance it may look as if

$439 \mathrm{WGNP}_{75} \mathrm{MZNP}_{25}$ and $\mathrm{WGNP}_{50} \mathrm{MZNP}_{50}$ display foaming characteristics intermediate to those of

440 WGNP $_{100}$ and $\mathrm{MZNP}_{100}$, the hybrid particles had performed worse than expected. Indeed, the 
441 foam stability of WGNP ${ }_{75} M_{2 N P_{25}}$ was substantially lower than that of WGNP 100 while that of

442 WGNP $_{50} \mathrm{MZNP}_{50}$ was even almost as poor as that of $\mathrm{MZNP}_{100}$.

443 Figure 5 a illustrates that this was not what we expected. Indeed, a WGNP 100 suspension 444 containing $0.03 \%$ protein had excellent foam stability. That WGNP $75 M_{2 N P_{25}}$ and $W_{G N P_{50}} M_{Z N P_{50}}$ 445 still consisted of $75 \%$ and $50 \%$ of gliadin protein and that their foaming characteristics were tested 446 at $0.10 \%$ protein implies that the zein proteins in the mixed gliadin-zein NPs had a detrimental 447 effect on their functionality at the air-water interface, even if the hybrid NPs had SH intermediate

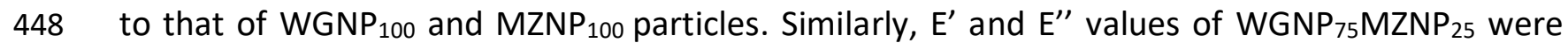
449 substantially lower than those of $W_{G N P_{100}}$, while $E^{\prime}$ and $E^{\prime \prime}$ of $W_{G N P_{50}} M_{2 N P_{50}}$ were rather similar 450 to those of $\mathrm{MZNP}_{100}$ (Figure 7c-d). Figure $7 \mathrm{~b}$ shows that no differences in the evolution of surface 451 tension over time of the different mixed particles, which indicates that the observed differences 452 in $E^{\prime}$ and $E^{\prime \prime}$ are due to inherent differences in film properties rather than to differences in surface 453 pressure. All this is of course in line with the observed foaming properties of these mixed gliadin454 zein NPs. It thus seems that when NPs contain zein this results in a weakly viscoelastic protein 455 film and thus in low foam stability. This finding not only renders fundamental insights in the 456 behavior of protein based NPs at interfaces, but possibly presents some interesting application 457 potential. Indeed, hydrophobic particles, such as those made of hydrophobized silica are useful 458 in anti-foaming applications $[56,57,58]$. However, to the best of our knowledge there are no 459 published reports on edible protein based anti-foaming agents, which may be relevant for food 460 systems. Our findings suggest that MZNPs may have such application potential.

\section{CONCLUSIONS}


464 WGNPs were larger and had a more homogeneous size distribution than MZNPs, while the latter 465 had higher ZP than the former. These differences could partly be ascribed to differences in $\mathrm{pH}$, 466 although MZNPs at low pH still had much higher ZP than WGNPs at low pH. More important is 467 that MZNPs had much higher SH than WGNPs, regardless of the $\mathrm{pH}$ value. Defatting prior to 468 particle production revealed that wheat and maize endogenous lipids did not impact size and 469 surface charge of the NPs produced. More importantly, no impact on the SH of the NPs was 470 observed. Thus, the impact of endogenous lipids was limited at best and the high SH of the MZNPS 471 could be ascribed solely to the proteins present. It should be noted here that the properties of 472 the obtained NPs evidently depend on the properties of the protein material from which they are 473 made. Here, WG proteins were extracted from a commercial wheat gluten sample, while MZ 474 proteins were used as supplied (see section 2.1). The pre-treatment of these protein sources 475 might to some extent determine the characteristics of the particles they result in. Future research 476 to further investigate this would be desirable. Regardless, WGNPs here had excellent foaming 477 capacity and foam stability, while barely any foam could be formed with MZNPs. The foaming 478 properties of mixed gliadin-zein particles with intermediate SHs were worse than expected based 479 on their relatively high gliadin protein content. Thus, SH surely is not the only factor which 480 determines the air-water interfacial properties of plant proteins based NPs. Moreover, the 481 presence of zein proteins in NPs resulted in poor foam stability when these particles adsorbed at 482 air-water interfaces. Interestingly, all these observations regarding foaming characteristics could 483 be related to the build-up of a viscoelastic protein film at the interface upon adsorption of NPs. 484 Indeed, WGNPs had much higher E values than MZNPs, which was in line with the superior 
foaming properties of the former. This suggested that for a suspension of NPs based on gliadins

or zeins to be able to efficiently stabilize interfaces, they need to at least partially disintegrate and spread at the interface, thereby mutually interacting and forming a coherent viscoelastic protein

488 film. This in itself is a worthwhile observation as it shows that the Pickering effect by which rigid NPs typically stabilize interfaces might not be the sole mechanism in play in systems where NP suspensions are produced from flexible surface-active biopolymers. We have shown that the 491 structural (size, surface charge, surface hydrophobicity) properties of protein based NPs to a large extent but not fully explain their air-water interfacial characteristics. This illustrates the importance of thoroughly characterizing both the structural and functional properties in order to 494 better understand their behavior in food systems. In a follow-up paper, we will conduct an indepth investigation on how WGNPs adsorb and mutually interact at air-water interfaces and how 496 this relates to their structural properties. Even if more research in this area is needed, it was 497 clearly shown that controlled aggregation of some plant proteins, leading to a homogeneously 498 distributed dispersion of NPs, is a valid strategy for improving the foaming properties of such 499 otherwise largely insoluble and therefore poorly functional proteins in aqueous systems.

502 A.G.B. Wouters thanks the Research Foundation - Flanders (FWO, Brussels, Belgium) for a 503 position as postdoctoral research fellow. J.A. Delcour holds the W.K. Kellogg Chair in Cereal 504 Science and Nutrition at KU Leuven. This work is part of the Methusalem program "Food for the 505 Future" at KU Leuven. 


\section{REFERENCES}

508 (1) M.A. Bos, T. van Vliet, Interfacial rheological properties of adsorbed protein layers and 509 surfactants: A review, Adv. Colloid Interface Sci. 91 (2001) 437-471.

510 (2) P. Wilde, A. Mackie, F. Husband, P. Gunning, V. Morris, Proteins and emulsifiers at liquid 511 interfaces, Adv. Colloid Interface Sci. 108 (2004) 63-71.

512 (3) B.S. Murray, Rheological properties of protein films, Curr. Opin. Colloid Interface Sci. 16 (2011) 513 27-35.

514 (4) S.U. Pickering, Cxcvi.-emulsions, Journal of the Chemical Society, Transactions 91 (1907) 20015152021.

516 (5) W. Ramsden, Separation of solids in the surface-layers of solutions and 'suspensions' 517 (observations on surface-membranes, bubbles, emulsions, and mechanical coagulation). -518 preliminary account, Proceedings of the Royal Society of London 72 (1903) 156-164.

519 (6) R. Aveyard, B.P. Binks, J.H. Clint, Emulsions stabilised solely by colloidal particles, Adv. Colloid 520 Interface Sci. 100-102 (2003) 503-546.

521 (7) B.P. Binks, Particles as surfactants-similarities and differences, Curr. Opin. Colloid Interface 522 Sci. 7 (2002) 21-41.

523 (8) S. Lam, K.P. Velikov, O.D. Velev, Pickering stabilization of foams and emulsions with particles 524 of biological origin, Curr. Opin. Colloid Interface Sci. 19 (2014) 490-500.

(9) I. Tavernier, W. Wijaya, P. Van der Meeren, K. Dewettinck, A.R. Patel, Food-grade particles for emulsion stabilization, Trends Food Sci. Technol. 50 (2016) 159-174.

(10) J. Xiao, Y. Li, Q. Huang, Recent advances on food-grade particles stabilized pickering emulsions: Fabrication, characterization and research trends, Trends Food Sci. Technol. 55 (2016) 48-60.

(11) B.P. Binks, S.O. Lumsdon, Stability of oil-in-water emulsions stabilised by silica particles, Physical Chemistry Chemical Physics 1 (1999) 3007-3016.

(12) B.P. Binks, S.O. Lumsdon, Pickering emulsions stabilized by monodisperse latex particles: Effects of particle size, Langmuir 17 (2001) 4540-4547.

(13) E. Dickinson, Biopolymer-based particles as stabilizing agents for emulsions and foams, Food Hydrocolloid. 68 (2017) 219-231.

(14) E. Dickinson, Food emulsions and foams: Stabilization by particles, Curr. Opin. Colloid Interface Sci. 15 (2010) 40-49.

(15) J.L. Lusk, F.B. Norwood, Some economic benefits and costs of vegetarianism, Agricultural and Resource Economics Review 38 (2009) 109-124.

(16) N. Alexandratos, J. Bruinsma. World agriculture: Towards 2030/2050. Prospects for food, nutrition, agriculture and major commodity groups. An fao perspective. Interim report. Food and Agriculture Organisation. 2006,

(17) M. Herrero, P. Gerber, T. Vellinga, T. Garnett, A. Leip, C. Opio, H.J. Westhoek, P.K. Thornton, J. Olesen, N. Hutchings, H. Montgomery, J.F. Soussana, H. Steinfeld, T.A. McAllister, Livestock and greenhouse gas emissions: The importance of getting the numbers right, Anim. Feed Sci. Technol. 166-67 (2011) 779-782.

(18) L. Reijnders, S. Soret, Quantification of the environmental impact of different dietary protein choices, American Journal of Clinical Nutrition 78 (2003) 664S-668S. 
(19) L. Day, Proteins from land plants - potential resources for human nutrition and food security, Trends Food Sci. Technol. 32 (2013) 25-42.

(20) A.G.B. Wouters, I. Rombouts, E. Fierens, K. Brijs, J.A. Delcour, Relevance of the functional properties of enzymatic plant protein hydrolysates in food systems, Compr. Rev. Food. Sci. Food Saf. 15 (2016) 786-800.

(21) I.J. Joye, D.J. McClements, Production of nanoparticles by anti-solvent precipitation for use in food systems, Trends Food Sci. Technol. 34 (2013) 109-123.

(22) M.G. Corradini, M. Demol, J. Boeve, R.D. Ludescher, I.J. Joye, Fluorescence spectroscopy as a tool to unravel the dynamics of protein nanoparticle formation by liquid antisolvent precipitation, Food Biophysics 12 (2017) 211-221.

(23) Y.-Q. Hu, S.-W. Yin, J.-H. Zhu, J.-R. Qi, J. Guo, L.-Y. Wu, C.-H. Tang, X.-Q. Yang, Fabrication and characterization of novel pickering emulsions and pickering high internal emulsions stabilized by gliadin colloidal particles, Food Hydrocolloid. 61 (2016) 300-310.

(24) I.J. Joye, V.A. Nelis, D.J. McClements, Gliadin-based nanoparticles: Fabrication and stability of food-grade colloidal delivery systems, Food Hydrocolloid. 44 (2015) 86-93.

(25) D. Peng, W. Jin, J. Li, W. Xiong, Y. Pei, Y. Wang, Y. Li, B. Li, Adsorption and distribution of edible gliadin nanoparticles at the air/water interface, J. Agric. Food Chem. 65 (2017) 2454-2460.

(26) N. Chatsisvili, A.P. Philipse, B. Loppinet, R.H. Tromp, Colloidal zein particles at water-water interfaces, Food Hydrocolloid. 65 (2017) 17-23.

(27) J.W.J. de Folter, M.W.M. van Ruijven, K.P. Velikov, Oil-in-water pickering emulsions stabilized by colloidal particles from the water-insoluble protein zein, Soft Matter 8 (2012) 6807-6815.

(28) A.R. Patel, E.C.M. Bouwens, K.P. Velikov, Sodium caseinate stabilized zein colloidal particles, J. Agric. Food Chem. 58 (2010) 12497-12503.

(29) Y. Zou, J. Guo, S.-W. Yin, J.-M. Wang, X.-Q. Yang, Pickering emulsion gels prepared by hydrogen-bonded zein/tannic acid complex colloidal particles, J. Agric. Food Chem. 63 (2015) 7405-7414.

(30) J. Xiao, X.a. Wang, A.J. Perez Gonzalez, Q. Huang, Kafirin nanoparticles-stabilized pickering emulsions: Microstructure and rheological behavior, Food Hydrocolloid. 54 (2016) 30-39.

(31) Y. Zou, Z. Wan, J. Guo, J. Wang, S. Yin, X. Yang, Modulation of the surface properties of protein particles by a surfactant for stabilizing foams, RSC Advances 6 (2016) 66018-66026.

(32) Y. Zou, C. van Baalen, X. Yang, E. Scholten, Tuning hydrophobicity of zein nanoparticles to control rheological behavior of pickering emulsions, Food Hydrocolloid. 80 (2018) 130-140.

(33) L. Dai, C. Sun, Y. Wei, L. Mao, Y. Gao, Characterization of pickering emulsion gels stabilized by zein/gum arabic complex colloidal nanoparticles, Food Hydrocolloid. 74 (2018) 239-248.

(34) L.J. Wang, S.W. Yin, L.Y. Wu, J.R. Qi, J. Guo, X.Q. Yang, Fabrication and characterization of pickering emulsions and oil gels stabilized by highly charged zein/chitosan complex particles (zccps), Food Chem. 213 (2016) 462-469.

(35) Y.M. Feng, Y. Lee, Surface modification of zein colloidal particles with sodium caseinate to stabilize oil-in-water pickering emulsion, Food Hydrocolloid. 56 (2016) 292-302.

(36) D. Peng, W. Jin, C. Tang, Y. Lu, W. Wang, J. Li, B. Li, Foaming and surface properties of gliadin nanoparticles: Influence of ph and heating temperature, Food Hydrocolloid. (2018).

(37) I.J. Joye, V.A. Nelis, D.J. McClements, Gliadin-based nanoparticles: Stabilization by postproduction polysaccharide coating, Food Hydrocolloid. 43 (2015) 236-242. 
(38) AOAC. Official methods of analysis. Method 990.03., Association of Official Analytical Chemists: Washington, DC, USA, 1995.

(39) AACCI. Aacc international method 44-19-01. Moisture - air-oven method, drying at $135^{\circ} \mathrm{C}$, American Association of Cereal Chemists, 2018.

(40) E.G. Bligh, W.J. Dyer, A rapid method of total lipid extraction and purification, Canadian Journal of Biochemistry and Physiology 37 (1959) 911-917.

(41) I.S. Khattab, F. Bandarkar, M.A.A. Fakhree, A. Jouyban, Density, viscosity, and surface tension of water+ethanol mixtures from 293 to 323k, Korean J. Chem. Eng. 29 (2012) 812-817.

(42) R. Belda, J.V. Herraez, O. Diez, A study of the refractive index and surface tension synergy of the binary water/ethanol: Influence of concentration, Physics and Chemistry of Liquids 43 (2005) 91-101.

(43) G. Akerlof, Dielectric constants of some organic solvent-water mixtures at various temperatures, Journal of the American Chemical Society 54 (1932) 4125-4139.

(44) A.G.B. Wouters, I. Rombouts, M. Legein, E. Fierens, K. Brijs, C. Blecker, J.A. Delcour, Air-water interfacial properties of enzymatic wheat gluten hydrolyzates determine their foaming behavior, Food Hydrocolloid. 55 (2016) 155-162.

(45) A.G.B. Wouters, I. Rombouts, E. Fierens, K. Brijs, C. Blecker, J.A. Delcour, B.S. Murray, Foaming and air-water interfacial characteristics of solutions containing both gluten hydrolysate and egg white protein, Food Hydrocolloid. 77 (2018) 176-186.

(46) E.H. Lucassen-Reynders, J. Benjamins, V.B. Fainerman, Dilational rheology of protein films adsorbed at fluid interfaces, Curr. Opin. Colloid Interface Sci. 15 (2010) 264-270.

(47) E.H. Lucassen-Reynders, D.T. Wasan, Interfacial viscoelasticity in emulsions and foams, Food Structure 12 (1993) 1-12.

(48) A. Ghisaidoobe, S. Chung, Intrinsic tryptophan fluorescence in the detection and analysis of proteins: A focus on förster resonance energy transfer techniques, Int. J. Mol. Sci. 15 (2014) 22518-22538.

(49) J.R. Lakowicz. Protein fluorescence. In Principles of fluorescencen spectroscopy, Lakowicz, J.R., Eds.; Springer US, 2006, 529-575.

(50) H.-D. Belitz, W. Grosch, P. Schieberle. Food chemistry, fourth; Springer-Verlag: Berlin, Germany, 2009; 563-616; 670-745 p.

(51) R. Shukla, M. Cheryan, Zein: The industrial protein from corn, Industrial Crops and Products 13 (2001) 171-192.

(52) N. Alizadeh-Pasdar, E.C.Y. Li-Chan, Comparison of protein surface hydrophobicity measured at various ph values using three different fluorescent probes, J. Agric. Food Chem. 48 (2000) 328334.

(53) A. Chakrabarti, Fluorescence of spectrin-bound prodan, Biochemical and Biophysical Research Communications 226 (1996) 495-497.

(54) J. Maldonado-Valderrama, J.M.R. Patino, Interfacial rheology of protein-surfactant mixtures, Curr. Opin. Colloid Interface Sci. 15 (2010) 271-282.

(55) Y. Zou, Z. Wan, J. Guo, J. Wang, S. Yin, X. Yang, Tunable assembly of hydrophobic protein nanoparticle at fluid interfaces with tannic acid, Food Hydrocolloid. 63 (2017) 364-371.

(56) S.I. Karakashev, M.V. Grozdanova, Foams and antifoams, Adv. Colloid Interface Sci. 176-177 (2012) 1-17. 
635 (57) K. Koczo, J.K. Koczone, D.T. Wasan, Mechanisms for antifoaming action in aqueous systems 636 by hydrophobic particles and insoluble liquids, J. Colloid Interface Sci. 166 (1994) 225-238.

637 (58) R.J. Pugh, Foaming, foam films, antifoaming and defoaming, Adv. Colloid Interface Sci. 64 638 (1996) 67-142.

639 
642 Table 1: Z-average $(\mathrm{nm})$, polydispersity-index and zeta potential $(\mathrm{mV})$ values of wheat gliadin 643 and maize zein nanoparticle (NP) suspensions (WGNPs and MZNPs, respectively) at pH 4.5 and 6446.0 (pH unadjusted) for WGNPs and pH 4.5 (pH unadjusted) and 5.5 for MZNPs. Capital letters 645 represent significant $(P<\mathbf{0 . 0 5})$ differences of a given parameter between different samples. 646

\begin{tabular}{ccccc}
\hline & pH & Z-average $(\mathbf{n m})$ & $\begin{array}{c}\text { Polydispersity- } \\
\text { index }\end{array}$ & $\begin{array}{c}\text { Zeta potential } \\
(\mathbf{m V})\end{array}$ \\
\hline \multirow{2}{*}{ WGNPs } & 4.5 & $132.5 \pm 12.6^{\mathrm{A}}$ & $0.201 \pm 0.036^{\mathrm{A}}$ & $21.3 \pm 3.7^{\mathrm{B}}$ \\
\cline { 2 - 5 } & $6.0(\mathrm{pH}$ unadjusted) & $140.2 \pm 15.5^{\mathrm{A}}$ & $0.102 \pm 0.029^{\mathrm{B}}$ & $15.5 \pm 1.2^{\mathrm{C}}$ \\
\hline \multirow{2}{*}{ MZNPs } & $4.5(\mathrm{pH}$ unadjusted) & $96.6 \pm 5.4^{\mathrm{B}}$ & $0.186 \pm 0.031^{\mathrm{A}}$ & $44.4^{\mathrm{A}} \pm 4.6^{\mathrm{A}}$ \\
\cline { 2 - 5 } & 5.5 & $154.7 \pm 28.8^{\mathrm{A}}$ & $0.115 \pm 0.05^{\mathrm{B}}$ & $16.7 \pm 2.0^{\mathrm{BC}}$ \\
\hline
\end{tabular}


650 Table 2: Z-average $(\mathrm{nm})$, polydispersity-index and zeta potential $(\mathrm{mV})$ values of wheat gliadin 651 and maize zein nanoparticle (NP) suspensions (WGNPs and MZNPs, respectively) prepared from 652 non-defatted, treated (T) or defatted (D) gliadin and zein powders. Capital letters represent 653 significant $(P<0.05)$ differences of a given parameter between different samples. 654

\begin{tabular}{cccc}
\hline & Z-average $(\mathrm{nm})$ & Polydispersity-index & Zeta potential (mV) \\
\hline WGNPs & $139.6 \pm 6.6^{\mathrm{A}}$ & $0.111 \pm 0.034^{\mathrm{C}}$ & $13.9 \pm 2.3^{\mathrm{C}}$ \\
\hline T-WGNPs & $132.8 \pm 6.2^{\mathrm{A}}$ & $0.149 \pm 0.011^{\mathrm{BC}}$ & $15.6 \pm 1.1^{\mathrm{C}}$ \\
\hline D-WGNPs & $126.4 \pm 3.3^{\mathrm{A}}$ & $0.141 \pm 0.028^{\mathrm{BC}}$ & $14.3^{\mathrm{C}} \pm 0.9^{\mathrm{C}}$ \\
\hline MZNPs & $86.1 \pm 15.5^{\mathrm{B}}$ & $0.215 \pm 0.007^{\mathrm{A}}$ & $42.7 \pm 3.4^{\mathrm{A}}$ \\
\hline T-MZNPs & $75.8 \pm 13.0^{\mathrm{B}}$ & $0.242 \pm 0.043^{\mathrm{AB}}$ & $36.9 \pm 4.8^{\mathrm{AB}}$ \\
\hline D-MZNPs & $76.6 \pm 18.1^{\mathrm{B}}$ & $0.209 \pm 0.060^{\mathrm{AB}}$ & $30.9 \pm 3.2^{\mathrm{B}}$ \\
\hline
\end{tabular}


662 Table 3: Z-average $(\mathrm{nm})$, polydispersity-index and zeta potential $(\mathrm{mV})$ values of nanoparticle 663 (NP) suspensions based on $100 \%$ gliadin (WGNP 100 ), 75\% gliadin and 25\% zein (WGNP ${ }_{75} M_{2 N P_{25}}$ ), $66450 \%$ gliadin and $50 \%$ zein $\left(\mathrm{WGNP}_{50} \mathrm{MZNP}_{50}\right)$ or $100 \%$ zein $\left(\mathrm{MZNP}_{100}\right)$. Capital letters represent 665 significant $(P<\mathbf{0 . 0 5})$ differences of a given parameter between different samples.

666

\begin{tabular}{cccc}
\hline & Z-average $(\mathrm{nm})$ & Polydispersity-index & Zeta potential (mV) \\
\hline WGNP $_{100}$ & $134.9 \pm 12.9^{\mathrm{A}}$ & $0.137 \pm 0.040^{\mathrm{B}}$ & $15.9 \pm 2.3^{\mathrm{B}}$ \\
\hline WGNP $_{75} \mathbf{M Z N P}_{25}$ & $109.0 \pm 7.7^{\mathrm{B}}$ & $0.121 \pm 0.018^{\mathrm{B}}$ & $19.6 \pm 2.8^{\mathrm{B}}$ \\
\hline WGNP $_{50} \mathbf{M Z N P}_{50}$ & $92.0 \pm 10.0^{\mathrm{B}}$ & $0.179 \pm 0.066^{\mathrm{AB}}$ & $19.9 \pm 3.8^{\mathrm{B}}$ \\
\hline MZNP $_{100}$ & $94.1 \pm 13.5^{\mathrm{B}}$ & $0.214 \pm 0.016^{\mathrm{A}}$ & $44.2 \pm 3.0^{\mathrm{A}}$
\end{tabular}

667

668

669 
671

672 Figure 1: Intrinsic (a) and extrinsic (b) [induced by binding of 6-propionyl-2673 dimethylaminonaphthalene (PRODAN) to hydrophobic patches on the surface of proteins] 674 fluorescence spectra of gliadin and zein nanoparticle (NP) (WGNPs and MZNPs, respectively) 675 suspensions at $\mathrm{pH} 4.5$ and 6.0 (pH unadjusted) for WGNP and 4.5 ( $\mathrm{pH}$ unadjusted) and 5.5 for 676 MZNP. A.U. are arbitrary units.

678 Figure 2: Foaming and air-water interfacial properties of gliadin and zein nanoparticle (NP) 679 (WGNP and MZNP, respectively) suspensions (at $0.10 \% \mathrm{w}_{\text {protein }} / \mathrm{v}$ ) at $\mathrm{pH} 4.5$ and $6.0(\mathrm{pH}$ 680 unadjusted) for WGNPs and 4.5 ( $\mathrm{pH}$ unadjusted) and 5.5 for MZNPs. The top graph represents 681 the foam volume over time after vigorous stirring of the different samples (a) while the bottom 682 graphs represent the evolution of surface tension $(\gamma)(b)$ surface dilatational elastic $\left(E^{\prime}\right)(c)$ and viscous $\left(E^{\prime \prime}\right)$ (d) moduli over time, obtained through oscillatory drop shape tensiometry.

Figure 3: Intrinsic (a) and extrinsic (b) [induced by binding of 6-propionyl-2686 dimethylaminonaphthalene (PRODAN) to hydrophobic patches on the surface of proteins] 687 fluorescence spectra of gliadin and zein nanoparticle (NP) (WGNP and MZNP, respectively) 688 suspensions. NPs were produced from non-defatted gliadin and zein powders or from their defatted (D) or solvent treated (T) counterparts. A.U. are arbitrary units.

690

691 Figure 4: Foaming and air-water interfacial properties of gliadin and zein nanoparticle (NP) 692 (WGNP and MZNP, respectively) suspensions containing $0.10 \%$ protein. Nanoparticles (NPs) were 
produced from non-defatted gliadin and zein powders or from their defatted (D) or solvent

694 treated $(T)$ counterparts. The top graph represents the foam volume over time after vigorous 695 stirring of the different samples (a) while the bottom graphs represent the evolution of surface 696 tension $(\gamma)(b)$, surface dilatational elastic ( $\left.E^{\prime}\right)(c)$ and viscous ( $\left.E^{\prime \prime}\right)(d)$ moduli over time, obtained 697 through oscillatory drop shape tensiometry.

699 Figure 5: Foaming properties of gliadin and zein nanoparticle (NP) (WGNP and MZNP, 700 respectively) suspensions. NPs were produced from non-defatted gliadin and zein powders or 701 from their defatted (D) or solvent treated ( $T$ ) counterparts. The top graph represents the foam 702 volume over time of $\mathrm{pH}$ unadjusted WGNP, D-GNP and T-GNP suspensions containing $0.03 \%$ protein (a) while the bottom graph represents the foam volume of MZNP, D-MZNP and T-MZNP 704 suspensions containing $0.10 \%$ protein at $\mathrm{pH} 5.5$ (b).

705

Figure 6: Intrinsic (a) and extrinsic (b) [induced by binding of 6-propionyl-2707 dimethylaminonaphthalene (PRODAN) to hydrophobic patches on the surface of proteins] 708 fluorescence spectra of nanoparticle (NP) suspensions produced with protein stock solutions 709 containing only wheat gliadin $\left(\mathrm{WGNP}_{100}\right)$, only maize zein $\left(\mathrm{MZNP}_{100}\right), 75 \%$ gliadin and $25 \%$ zein 710 (WGNP $75 \mathrm{MZNP}_{25}$ ) or $50 \%$ gliadin and $50 \%$ zein $\left(\mathrm{WGNP}_{50} \mathrm{MZNP}_{50}\right)$. A.U. are arbitrary units.

712 Figure 7: Foaming and air-water interfacial properties of nanoparticle (NP) suspensions 713 containing $0.10 \%$ protein produced with stock solutions containing only wheat gliadin (WGNP100), 714 only maize zein (MZNP 100 ), 75\% gliadin and 25\% zein (WGNP $75 \mathrm{MZNP}_{25}$ ) or 50\% gliadin and 50\% 


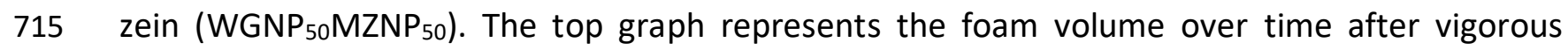
716 stirring of the different samples (a) while the bottom graphs represent the evolution of surface

717 tension $(\gamma)(b)$, surface dilatational elastic $\left(E^{\prime}\right)(c)$ and viscous $\left(E^{\prime \prime}\right)(d)$ moduli over time obtained 718 through oscillatory drop shape tensiometry.

719 

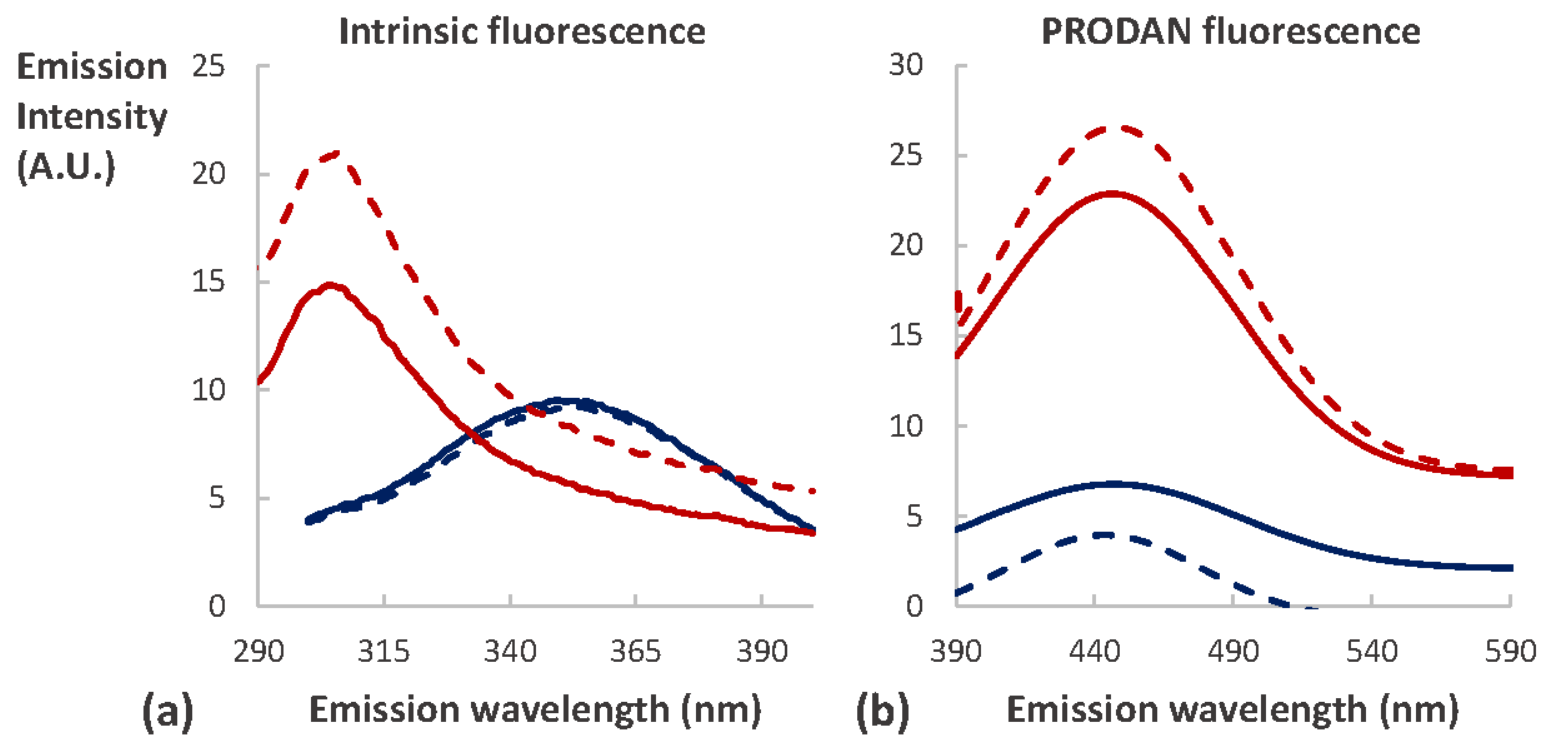

- - - WGNP pH $4.5-$ WGNP pH 6.0 MZNP pH 4.5 - - MZNP pH 5.5 


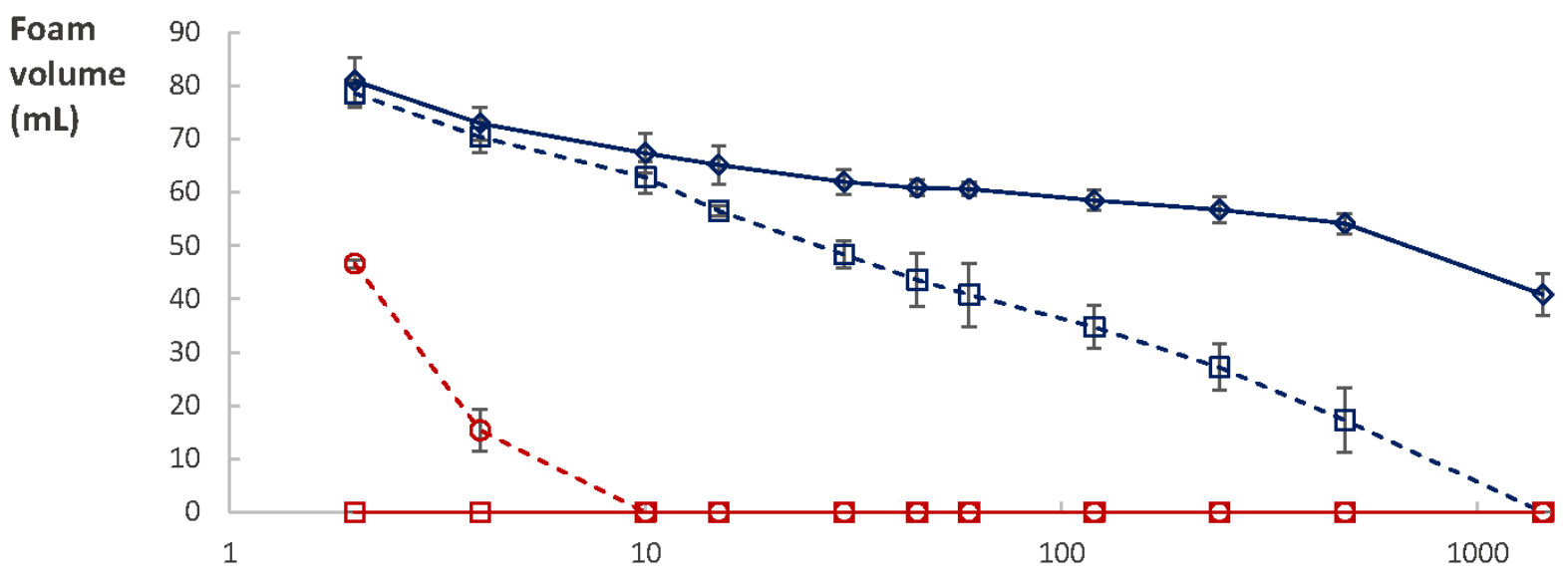

(a)

Time (min)

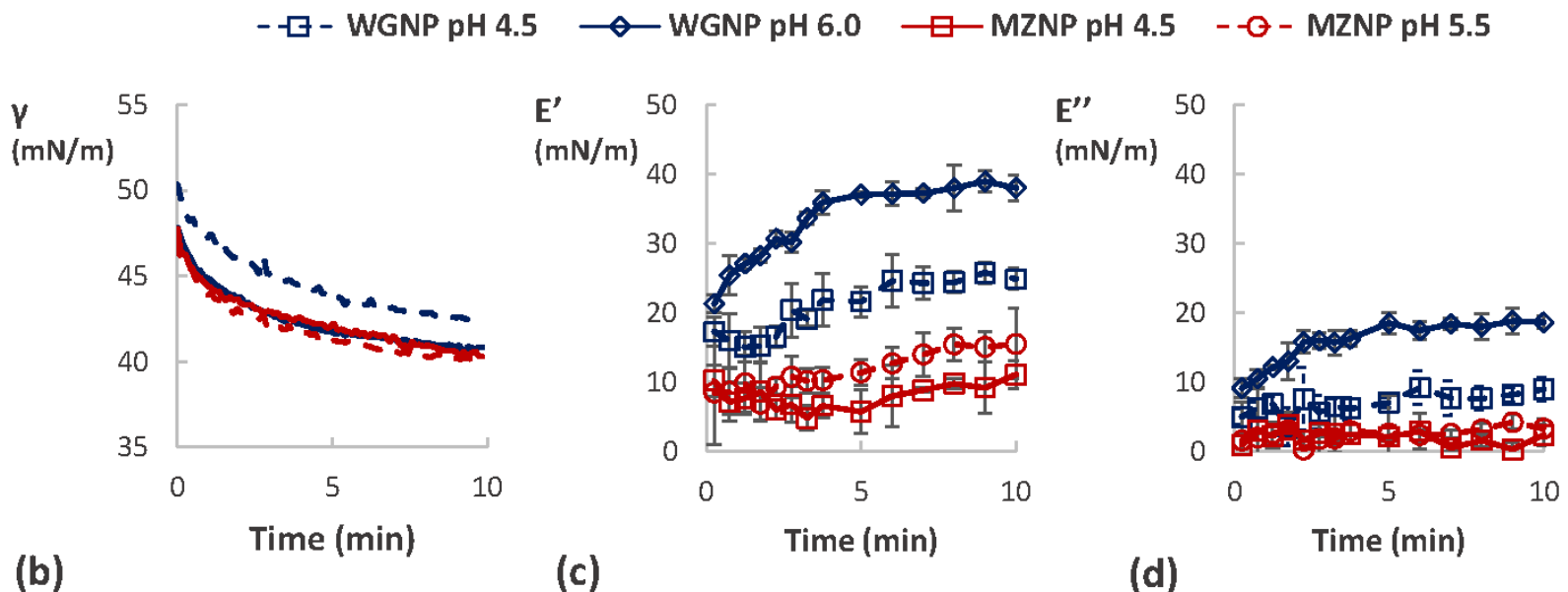



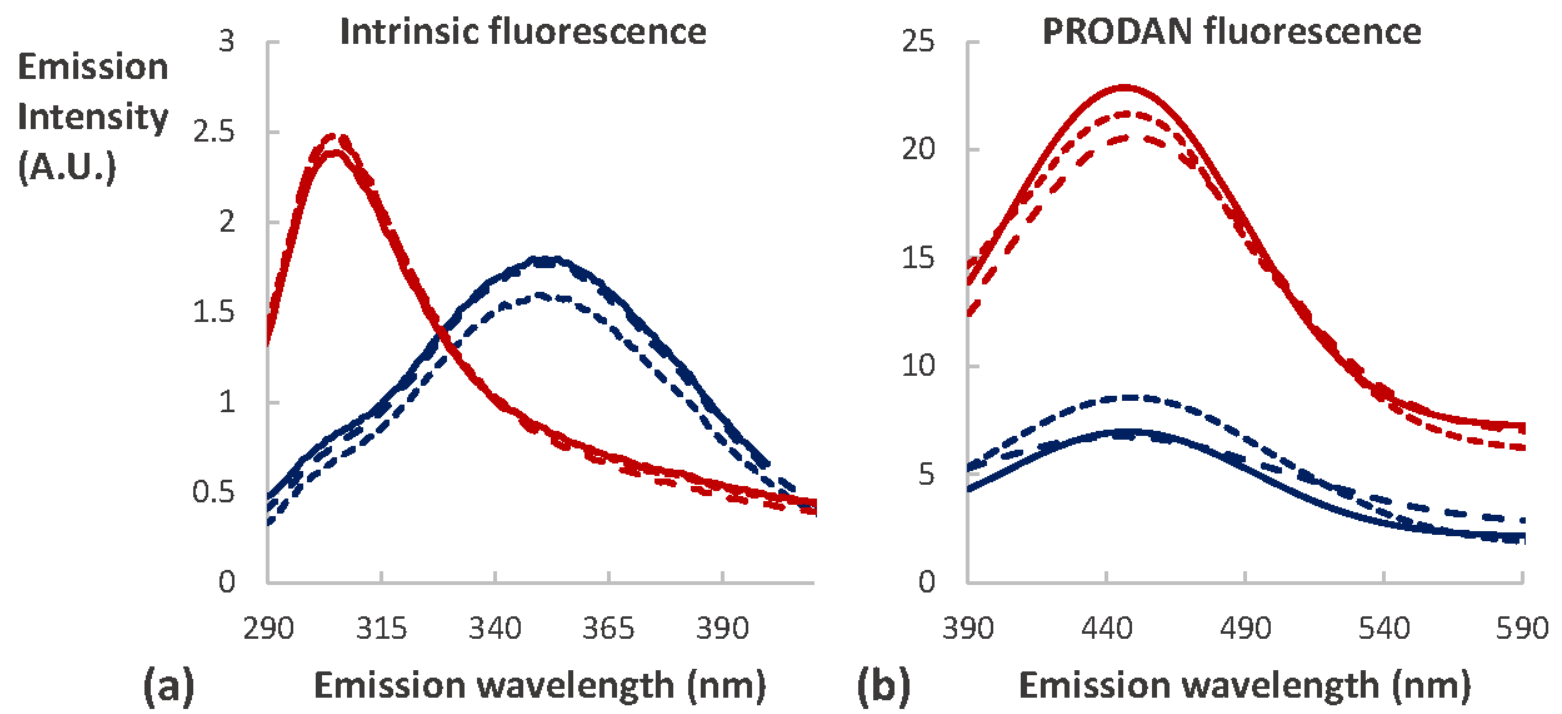

(b) Emission wavelength (nm)

MZNP ---- T-MZNP - - - D-MZNP 
FIGURE 4

740

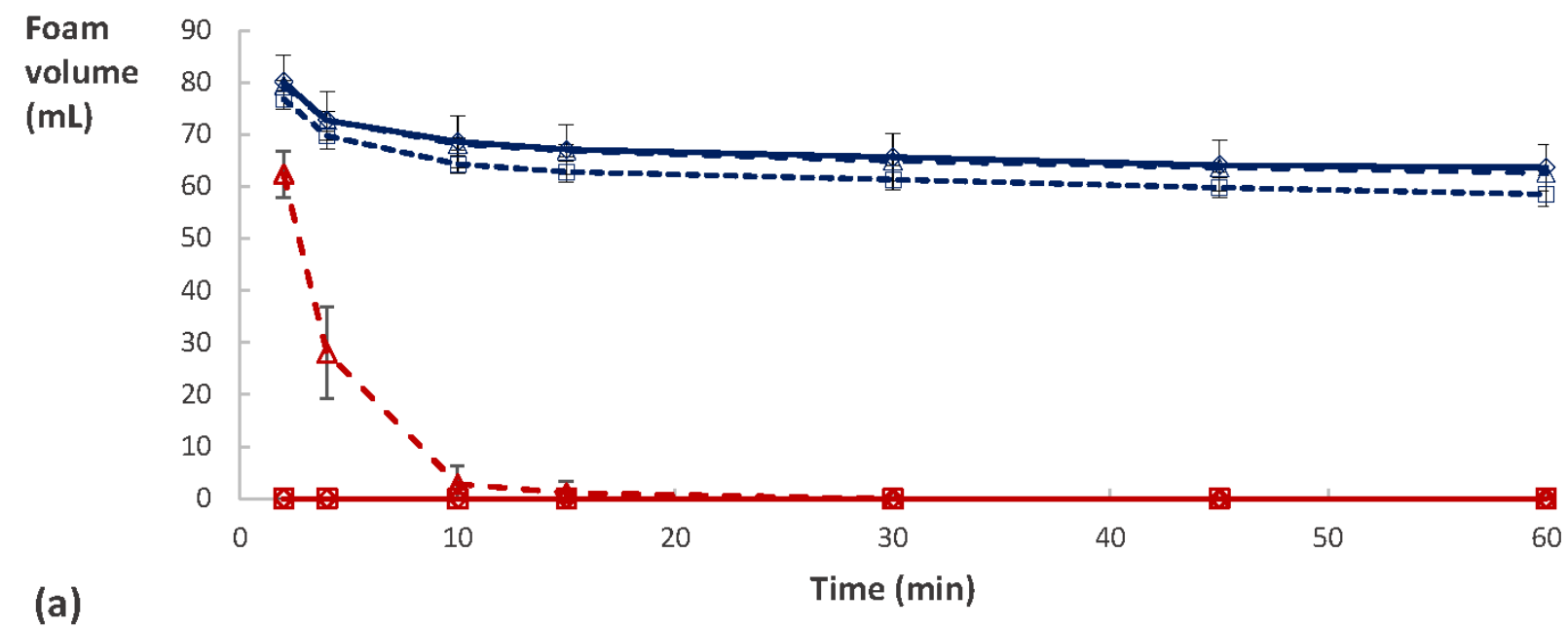

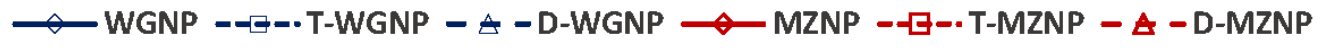

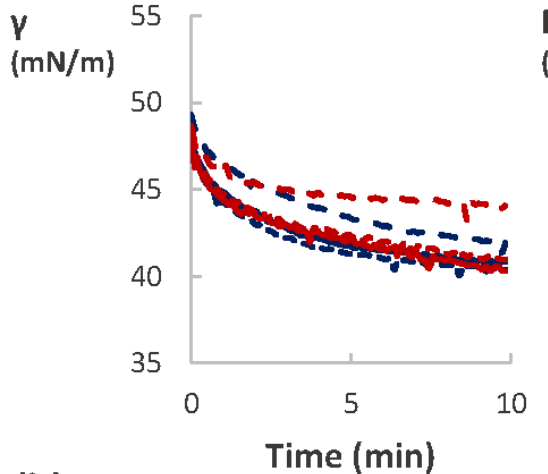

741

(b)

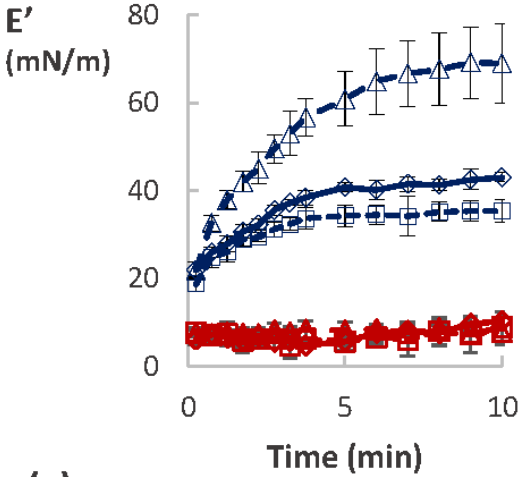

(c)

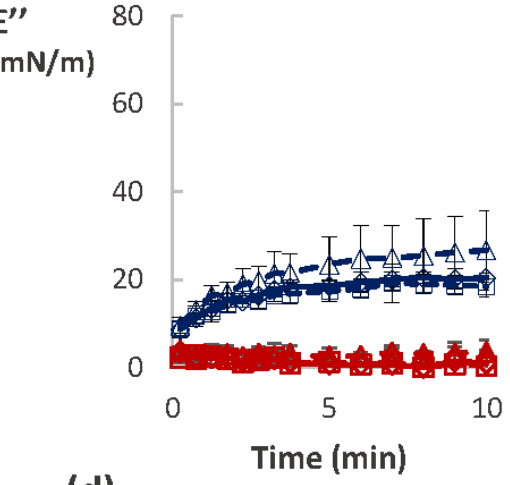

(d) 


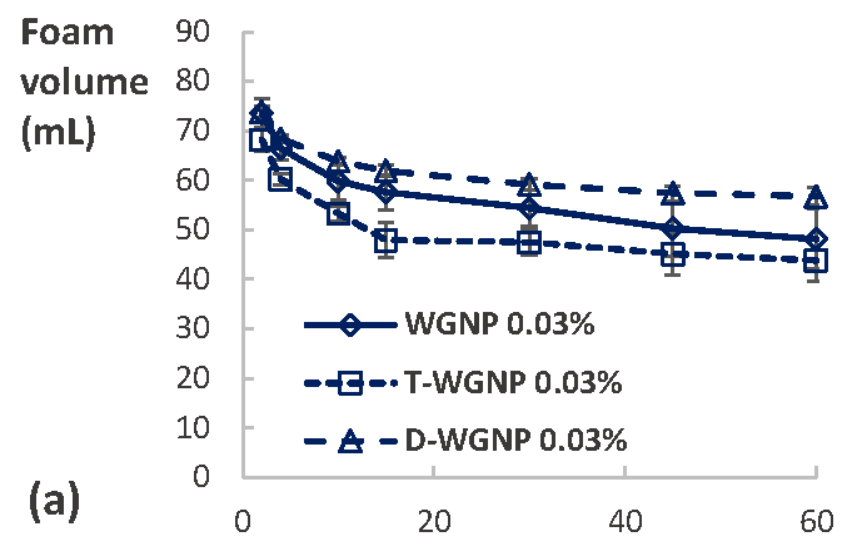

(b)

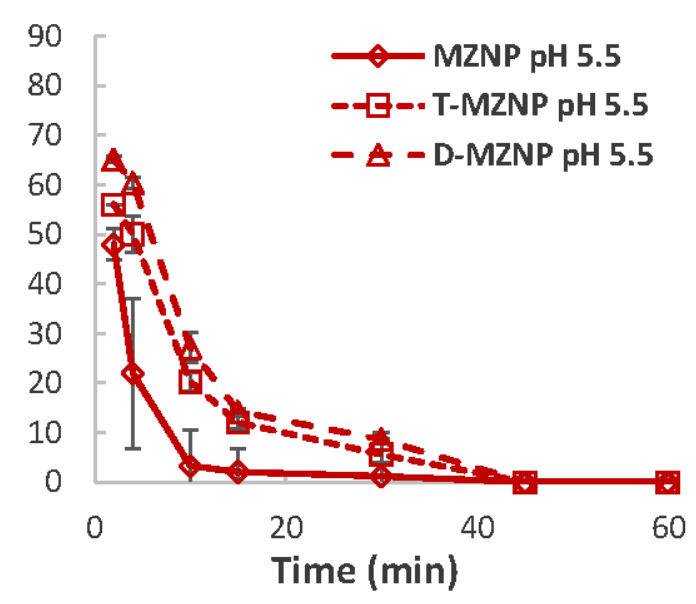



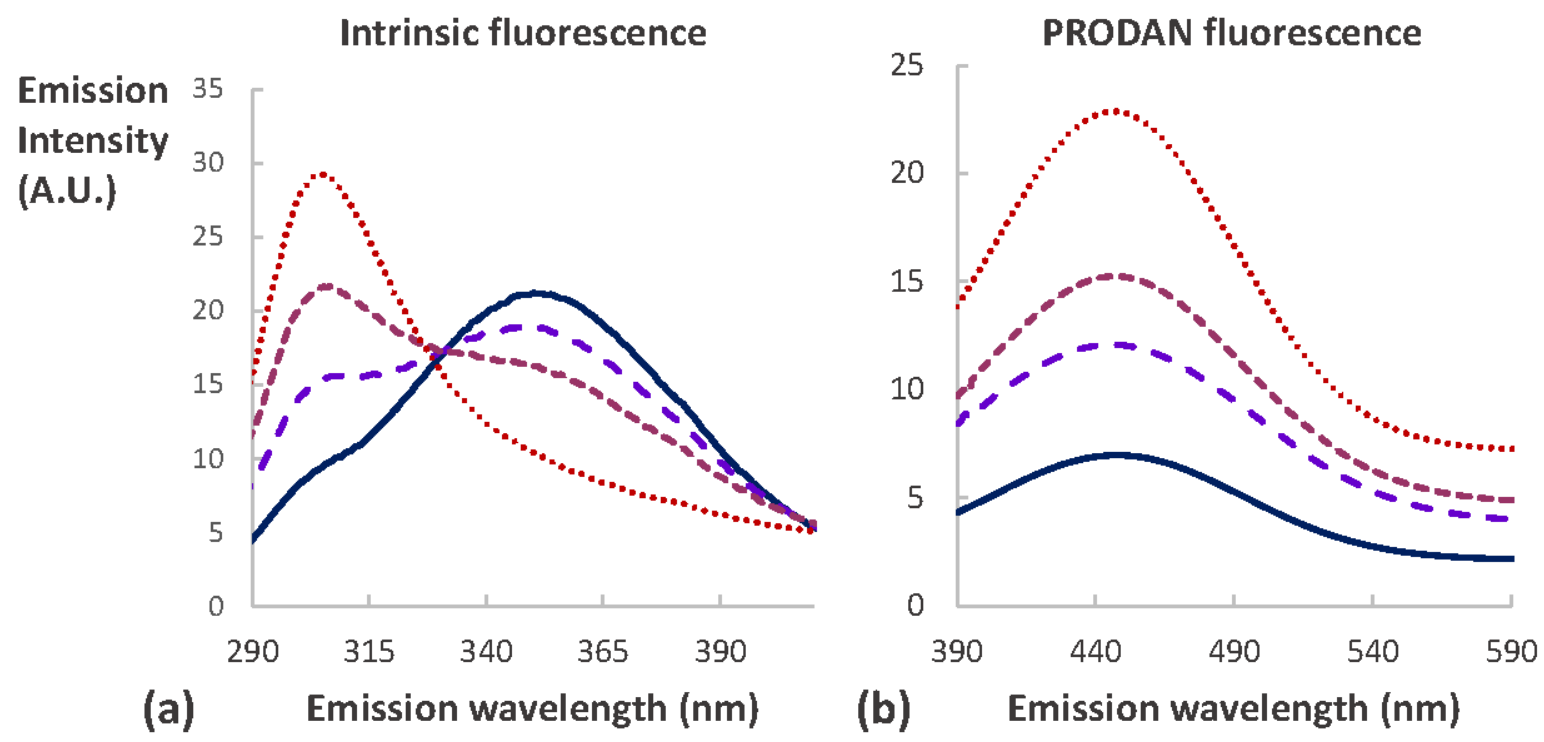

(a) Emission wavelength $(\mathrm{nm})$

(b) Emission wavelength (nm) 


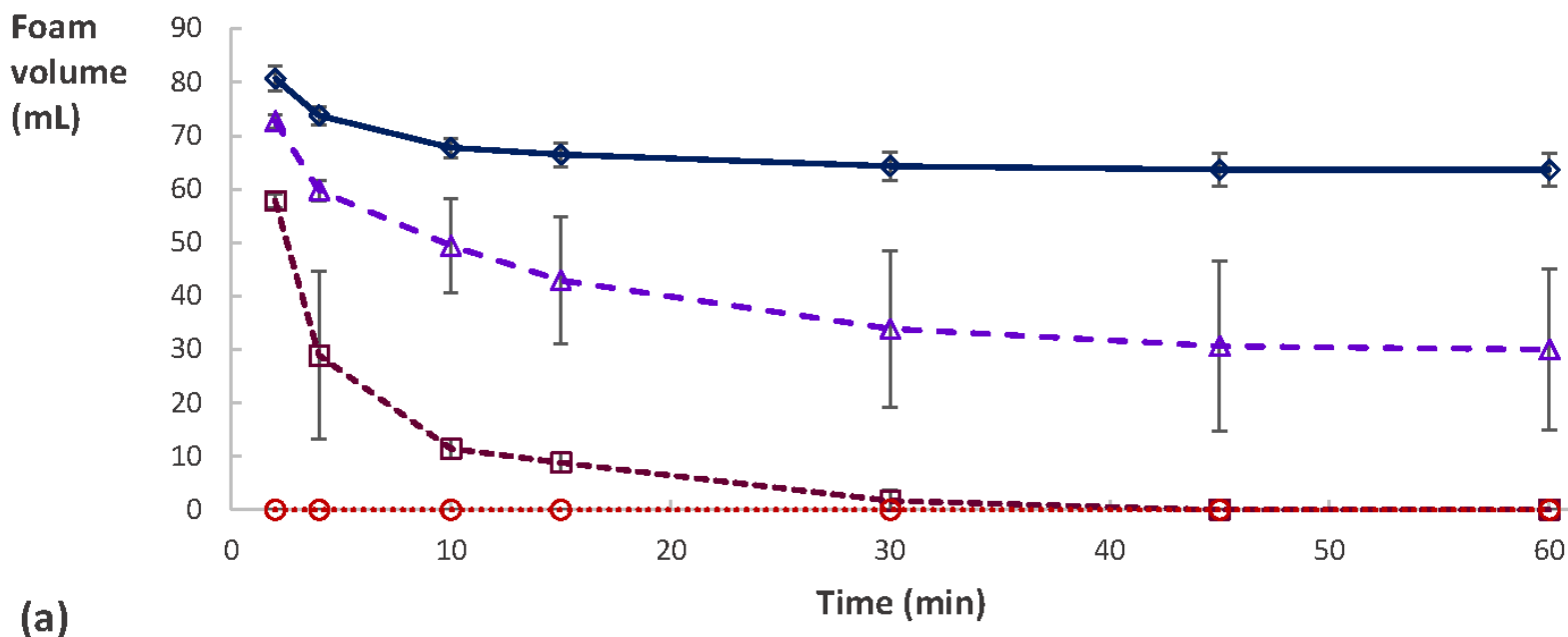

(a)

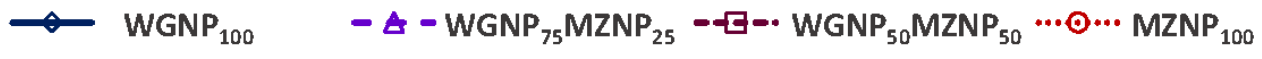

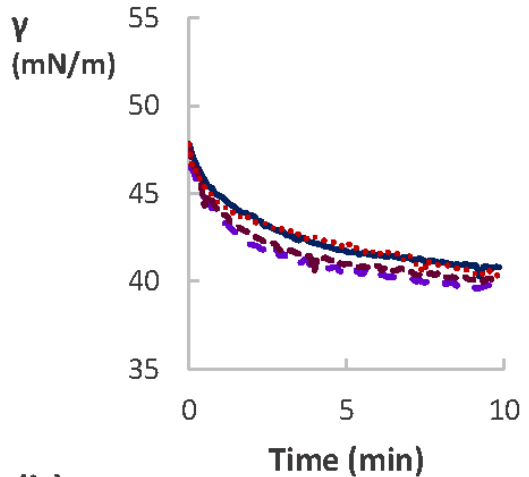

755

(b)

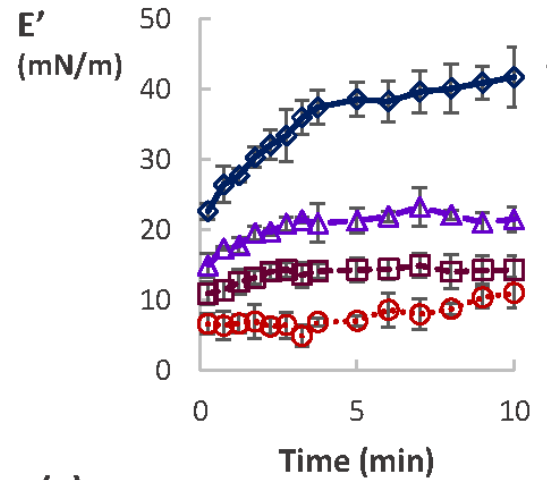

(c)

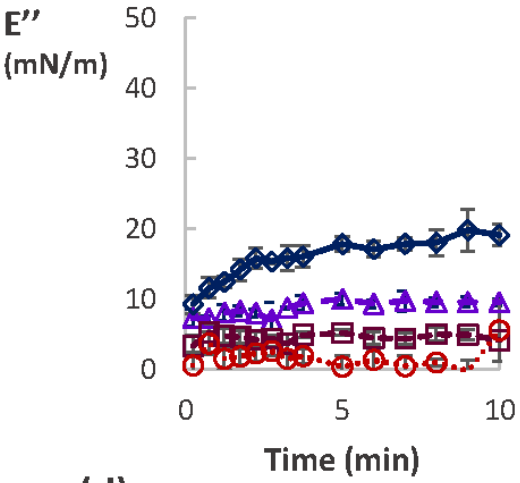

756

757 